Article

\title{
Retropharyngeal Lymph Node Involvement in Oropharyngeal Carcinoma: Impact upon Risk of Distant Metastases and Survival Outcomes
}

\author{
Zsuzsanna Iyizoba-Ebozue ${ }^{1,+}{ }^{,}$, Louise J. Murray ${ }^{1,2,+}$, Moses Arunsingh ${ }^{1}$, Karen E. Dyker ${ }^{1}$, \\ Sriram Vaidyanathan ${ }^{3}$, Andrew F. Scarsbrook ${ }^{2,3}$ and Robin J. D. Prestwich $1, *$ (i) \\ 1 Department of Clinical Oncology, Leeds Cancer Centre, Leeds LS97TF, UK; \\ zsuzsanna.iyizoba@nhs.net (Z.I.-E.); louise.murray8@nhs.net (L.J.M.); 85moses@gmail.com (M.A.); \\ karen.dyker@nhs.net (K.E.D.) \\ 2 Leeds Institute of Medical Research at St James's, University of Leeds, Leeds LS97TF, UK; \\ a.scarsbrook@nhs.net \\ 3 Department of Nuclear Medicine and Radiology, Leeds Cancer Centre, Leeds LS97TF, UK; \\ svaidyanathan@nhs.net \\ * Correspondence: robin.prestwich@nhs.net \\ + These authors contributed equally.
}

Received: 30 September 2019; Accepted: 23 December 2019; Published: 29 December 2019

\begin{abstract}
The influence of retropharyngeal lymph node (RPLN) involvement on prognosis in oropharyngeal carcinoma remains poorly defined. The aim of this study was to assess the impact of RPLN involvement upon outcomes. A single-centre retrospective analysis of 402 patients with oropharyngeal carcinoma treated nonsurgically between 2010 and 2017 was performed. All had a baseline 2-[fluorine-18]-fluoro-2-deoxy-D-glucose (FDG) PET-CT and contrast-enhanced MRI and/or CT. RPLN status was determined by radiology review of cases with reported abnormal RPLN. Multivariate backwards logistic regression was used to examine impact on outcomes of factors. Abnormal RPLNs were identified in 40/402 (10\%) of patients. Median follow up was 42.9 months. RPLN involvement was associated with inferior 3 year outcomes for overall survival (OS) $(67.1 \% \mathrm{vs}$. $79.1 \%, p=0.006)$ and distant metastases-free survival (DMFS) $(73.9 \%$ versus $88.0 \%, p=0.011)$, with no significant difference in local control $(81.6 \%$ vs. $87.7 \%, p=0.154)$ or regional control $(80.7 \%$ vs. $85.4 \%$, $p=0.252$ ). On multivariate analysis abnormal RPLN, no concurrent chemotherapy and ongoing smoking were associated with inferior DMFS and OS, while advanced T stage was also associated with inferior OS. In summary, RPLN involvement, present in $10 \%$ of patients, was an independent prognostic factor for the development of distant disease failure translating into inferior OS. These findings need confirmation in future studies.
\end{abstract}

Keywords: oropharynx cancer; radiotherapy; chemotherapy; lymph node; retropharyngeal; distant metastases; survival

\section{Introduction}

Nonsurgical treatment with radiotherapy and chemotherapy is a standard of care for the management of oropharyngeal carcinoma [1]. Human papilloma virus (HPV)-related oropharyngeal carcinoma has a more favourable prognosis than non-HPV-related disease [1,2]. There has been considerable interest in exploring "de-escalation" strategies for better disease prognosis in view of the substantial toxicity of chemoradiotherapy [3-6]. The negative results of recent de-escalation studies seeking to replace concurrent cisplatin with cetuximab [3,6] emphasise the importance of accurate identification of patients with low-risk disease. The development of distant metastases remains a 
concern, even in apparently favourable prognosis disease [7]. Rates of distant metastases appear similar for HPV-positive and -negative disease, with controversy over whether HPV status influences the pattern of distant metastases [7-10].

Regional lymph node metastases from oropharyngeal squamous cell carcinoma can occur in cervical lymph nodes and retropharyngeal lymph node (RPLN) beds [11]. The retropharyngeal space extends from the skull base to the level of the $\mathrm{C} 3$ vertebra caudally, posterior to the constrictor muscles and anterior to prevertebral fascia [11]. RPLN involvement has been found to be limited to the lateral retropharyngeal compartment [12-16] and this is reflected in contouring guidelines [17]. The difficulty in surgical access to the retropharyngeal area limits data on the incidence of RPLN metastases [11]. Surgical series are small and restricted to highly selected operable patients [18,19], hence limiting their applicability to the wider group of oropharyngeal carcinoma. Imaging studies have reported a very variable incidence of RPLN involvement, with larger series reporting RPLN involvement in $9-21 \%$ of oropharyngeal carcinomas [12-14,20-23].

The American Joint Committee on Cancer (AJCC) TNM oropharynx staging system [24] does not include RPLN as a site of regional lymph nodes and RPLNs are not included as an independent prognostic factor. Recent treatment de-escalation studies have not excluded patients with RPLN involvement $[3,6]$. There is limited data regarding the prognostic influence of radiological RPLN involvement in oropharyngeal carcinoma. Some studies have suggested that RPLN involvement in patients with oropharyngeal carcinoma is associated with inferior survival and higher risk of development of distant metastatic disease $[13,15]$. The prognostic implications of RPLN in patients with HPV-related oropharyngeal disease are controversial, with some, but not all, studies suggesting a negative relationship $[12,15,20]$. Elucidating the prognostic impact of RPLN involvement is important to accurately stratify risk in oropharyngeal carcinoma. If RPLN involvement predicts inferior outcomes, this should be considered as an exclusion criterion from studies investigating treatment deintensification.

We have recently reported on the incidence and patterns of RPLN involvement in oropharyngeal carcinoma in a series of 402 patients treated with chemoradiotherapy who had baseline 2-[fluorine-18]-fluoro-2-deoxy-D-glucose (FDG) PET-CT along with an MRI and/or contrast-enhanced CT [16]. The purpose of this study was to analyse the impact of RPLN upon survival and disease outcomes.

\section{Results}

\subsection{Whole Cohort}

Table 1 summarises baseline demographics, tumour characteristics and treatment for the cohort of 402 patients with oropharyngeal carcinoma. Among patients, 382/402 (95.0\%) had stage III/IV disease according to the AJCC TNM seventh edition [25], 76/402 (18.9\%) received radiotherapy alone, $1 / 402(0.2 \%)$ received induction chemotherapy (ICT) followed by radiotherapy, 17/402 (4.2\%) received induction chemotherapy followed by concurrent chemotherapy and 308/402 (76.6\%) received concurrent chemotherapy without induction. Median follow up was 42.9 months ( $95 \%$ confidence interval: 39.9-45.9). For the whole cohort of 402 patients, 3 year overall survival (OS), local control, regional control and distant metastasis-free survival (DMFS) were 77.9\%, 87.0\%, 84.7\% and 86.6\%, respectively. In total, disease progression occurred in 99/402 (24.6\%) patients. This included 48 patients with local progression, 55 with regional lymph node progression and 48 who developed distant metastases. 
Table 1. Patient, disease and treatment characteristics.

\begin{tabular}{|c|c|c|c|c|}
\hline Characteristics & $\begin{array}{l}\text { Total Cohort } \\
\text { (Column \%) } \\
n=402\end{array}$ & $\begin{array}{c}\text { RP Lymph Node } \\
\text { Negative (Column \%) } \\
\text { n }=362\end{array}$ & $\begin{array}{c}\text { RP Lymph Node } \\
\text { Positive (Column \%) } \\
\text { n }=40\end{array}$ & $p$-Value \\
\hline Age & & & & \multirow{2}{*}{0.297} \\
\hline Median (range) & $57(24-84)$ & $57(24-84)$ & $56(37-73)$ & \\
\hline \multicolumn{4}{|l|}{ Gender } & \multirow{3}{*}{0.393} \\
\hline Male & 310 (77.1) & 277 (76.5) & $33(82.5)$ & \\
\hline Female & $92(22.9)$ & $85(23.5)$ & $7(17.5)$ & \\
\hline \multicolumn{4}{|l|}{ Smoking } & \multirow{5}{*}{0.868} \\
\hline Never & $114(28.4)$ & $103(28.5)$ & $11(27.5)$ & \\
\hline Former & $137(34.1)$ & $124(34.3)$ & $13(32.5)$ & \\
\hline Current & $133(33.1)$ & $118(32.6)$ & $15(37.5)$ & \\
\hline Not recorded & $18(4.5)$ & $17(4.7)$ & $1(2.5)$ & \\
\hline \multicolumn{4}{|l|}{ p16 status } & \multirow{4}{*}{0.266} \\
\hline Positive & $192(47.8)$ & $171(47.2)$ & $21(52.5)$ & \\
\hline Negative & $34(8.5)$ & $28(7.7)$ & $6(15.0)$ & \\
\hline Unknown & $176(43.8)$ & $163(45.0)$ & $13(32.5)$ & \\
\hline \multicolumn{4}{|l|}{ Tumour subsite } & \multirow{6}{*}{$0.002 *$} \\
\hline Tonsil & $241(60.0)$ & $219(60.5)$ & $22(55.0)$ & \\
\hline Base of Tongue & $135(33.6)$ & $123(34.0)$ & $12(30.0)$ & \\
\hline Vallecula & $9(2.2)$ & $9(2.5)$ & $0(0)$ & \\
\hline Postpharyngeal & $5(1.2)$ & $4(11.0)$ & $1(2.5)$ & \\
\hline Soft palate & $12(3.0)$ & $7(1.9)$ & $5(12.5)$ & \\
\hline \multicolumn{4}{|l|}{ T stage } & \multirow{5}{*}{0.194} \\
\hline $\mathrm{T} 1$ & $85(21.1)$ & $78(21.5)$ & $7(17.5)$ & \\
\hline $\mathrm{T} 2$ & $168(41.8)$ & $156(43.1)$ & $12(30.0)$ & \\
\hline T3 & $76(18.9)$ & $66(18.2)$ & $10(25.0)$ & \\
\hline $\mathrm{T} 4$ & $73(18.2)$ & $62(17.1)$ & $11(27.5)$ & \\
\hline \multicolumn{4}{|l|}{ N stage (AJCC 7th) } & \multirow{7}{*}{0.005} \\
\hline No & $41(10.2)$ & 39 (10.8) & $1(5.0)$ & \\
\hline N1 & 45 (11.2) & $44(12.2)$ & $2(2.5)$ & \\
\hline $\mathrm{N} 2 \mathrm{a}$ & $30(7.5)$ & $30(8.3)$ & $0(0)$ & \\
\hline $\mathrm{N} 2 \mathrm{~b}$ & $199(57.0)$ & $179(49.4)$ & $20(50.0)$ & \\
\hline $\mathrm{N} 2 \mathrm{c}$ & $74(18.4)$ & $59(16.3)$ & $15(37.5)$ & \\
\hline N3 & $13(3.2)$ & $11(3.0)$ & $2(5.0)$ & \\
\hline \multicolumn{4}{|l|}{ Stage (AJCC 7th) } & \multirow{5}{*}{0.207} \\
\hline 1 & $1(0.2)$ & $1(0.3)$ & $0(0)$ & \\
\hline 2 & $19(4.7)$ & $17(4.7)$ & $2(5.0)$ & \\
\hline 3 & 47 (11.7) & $47(13.0)$ & $0(0)$ & \\
\hline 4 & $335(83.3)$ & $297(82.0)$ & $38(95.0)$ & \\
\hline \multicolumn{4}{|l|}{ Histological grade } & \multirow{5}{*}{0.061} \\
\hline Well & $3(0.8)$ & $3(0.8)$ & $0(0)$ & \\
\hline Moderate & $74(18.4)$ & $62(17.1)$ & $12(30.0)$ & \\
\hline Poor & $297(73.9)$ & $272(75.1)$ & $25(62.5)$ & \\
\hline Unclassified & $28(6.9)$ & $25(6.9)$ & $3(7.5)$ & \\
\hline \multicolumn{4}{|c|}{ Induction chemotherapy } & \multirow{4}{*}{0.524} \\
\hline No & $384(95.6)$ & $345(95.3)$ & $39(97.5)$ & \\
\hline PF & $1(0.2)$ & $1(0.3)$ & $0(0)$ & \\
\hline TPF & $17(4.2)$ & $16(4.4)$ & $1(2.5)$ & \\
\hline \multicolumn{4}{|c|}{ Concurrent chemotherapy } & \multirow{3}{*}{0.707} \\
\hline No & $77(19.2)$ & $70(19.3)$ & $7(17.5)$ & \\
\hline Yes & $325(80.8)$ & $292(80.7)$ & $33(82.5)$ & \\
\hline
\end{tabular}

* Analysis comparing three groups (1. tonsil, 2. base of tongue and vallecula, 3. soft palate and posterior pharyngeal wall). AJCC $=$ American Joint Committee on Cancer; $\mathrm{PF}=$ platinum $/ 5$-fluorouracil; $\mathrm{RP}=$ retropharyngeal; $\mathrm{TPF}=$ docetaxel, cisplatin, 5-fluorouracil. Significant $p$-values highlighted in bold. 
All patients had a baseline staging PET-CT and also diagnostic imaging with MRI $(\mathrm{n}=339)$ and/or contrast-enhanced CT $(n=83)$. Details of the identification and imaging features of RPLNs have been previously reported [16] and are summarised here. Based upon review of clinical records, radiology reports and radiotherapy plans for a total of 43/402 patients with RPLN were identified. Following imaging review by a radiologist, 40/402 (10\%) patients were classified as having abnormal RPLN; 37/40 RPLN were FDG-avid on PET-CT (median SUV max $_{6.8}$ (range 3-26.3)) and 35/37 patients had a corresponding abnormal RPLN on diagnostic MRI and/or contrast-enhanced CT. Three patients had non-FDG avid abnormal RPLN identified on MRI (short axis: 5-9 mm). Abnormal RPLNs were located in the ipsilateral retropharyngeal area in only 32/40 patients, bilateral retropharyngeal regions in 5/40 patients and the contralateral retropharyngeal region in only $3 / 40$ patients.

RPLN involvement (40/402 (10\%) of patients) was associated with inferior 3 year outcomes for OS $(67.1 \%$ versus $79.1 \%, p=0.006)$ and DMFS $(73.9 \%$ versus $88.0 \%, p=0.011)$, with no significant difference in local control $(81.6 \%$ versus $87.7 \%, p=0.154)$ or regional control $(80.7 \%$ versus $85.4 \%, p=$ 0.252). Figure 1 provides the Kaplan-Meier survival curves illustrating outcomes for patients with or without RPLN involvement. Table 2 summarises the multivariate analysis of the whole cohort (not using p16 status as a factor due to missing data). RPLN involvement, no concurrent chemotherapy, ongoing smoking and more advanced T stage were associated with inferior OS. RPLN involvement, no concurrent chemotherapy and ongoing smoking were independently associated with inferior DMFS.
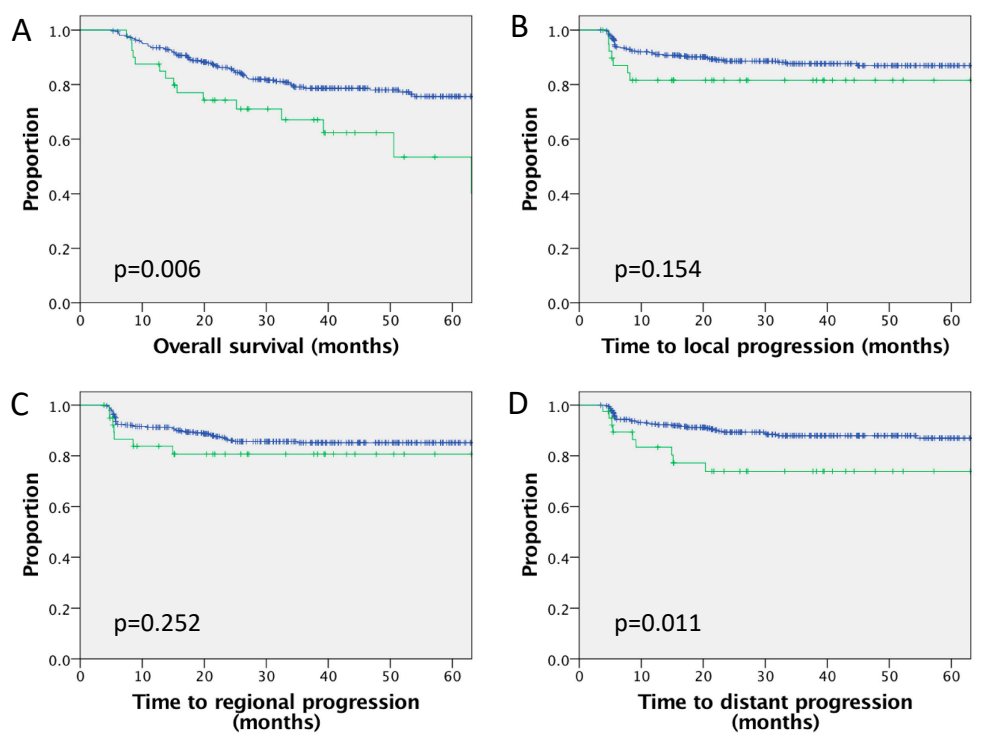

Figure 1. Survival outcomes for a cohort of 402 patients comparing outcomes with or without RPLN involvement. Kaplan-Meier curves for (A) overall survival, (B) local (primary tumour) progression, (C) regional (lymph node) progression and (D) distant metastatic progression. RPLN negative $(\mathrm{n}=362)$ in blue and RPLN positive $(n=40)$ in green.

Table 2. Predictors of distant metastases-free survival (DMFS) and overall survival (OS) in the whole cohort ( $\mathrm{n}=402$, including 40 patients with RPLN involvement). Univariate analysis and multivariate Cox proportional hazards analysis using backwards likelihood ratios of established prognostic factors. Factors included in analysis were age, sex, $\mathrm{T}$ and $\mathrm{N}$ stage, presence of RPLN, use of concurrent chemotherapy and smoking status.

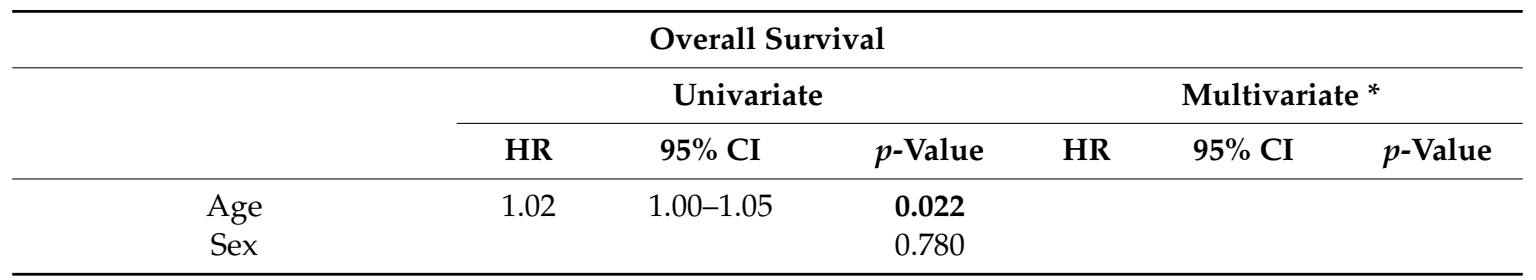


Table 2. Cont.

\begin{tabular}{|c|c|c|c|c|c|c|}
\hline \multicolumn{7}{|c|}{ Overall Survival } \\
\hline & \multicolumn{3}{|c|}{ Univariate } & \multicolumn{3}{|c|}{ Multivariate * } \\
\hline & HR & $95 \%$ CI & $p$-Value & HR & $95 \%$ CI & $p$-Value \\
\hline \multicolumn{7}{|l|}{ T stage } \\
\hline T2 vs. T1 & 2.27 & $1.05-4.88$ & 0.037 & 2.30 & $1.02-5.20$ & 0.046 \\
\hline T3 vs. T1 & 2.91 & $1.28-6.64$ & 0.011 & 2.40 & $1.00-5.79$ & 0.051 \\
\hline T4 vs. T1 & 4.62 & $2.11-10.43$ & $<0.001$ & 3.64 & $1.58-8.43$ & 0.003 \\
\hline \multicolumn{7}{|l|}{ N stage } \\
\hline N1 vs. N0 & 0.37 & $0.11-1.19$ & 0.094 & & & \\
\hline N2a vs. N0 & & & 0.230 & & & \\
\hline N2b vs. N0 & & & 0.991 & & & \\
\hline N2c vs. N0 & & & 0.344 & & & \\
\hline N3 vs. N0 & 2.37 & $0.84-6.65$ & 0.103 & & & \\
\hline RPLN status (+ve vs. -ve) & 2.13 & $1.22-3.71$ & 0.008 & 2.00 & $1.13-3.54$ & 0.018 \\
\hline $\begin{array}{l}\text { Concurrent chemotherapy } \\
\text { (no vs. yes) }\end{array}$ & 2.17 & $1.39-3.38$ & 0.001 & 2.02 & $1.29-3.19$ & 0.002 \\
\hline \multicolumn{7}{|l|}{ Smoking } \\
\hline Former vs. never & 1.92 & $0.97-3.83$ & 0.063 & & & \\
\hline Current vs. never & 4.23 & $2.27-8.00$ & $<0.001$ & 3.58 & $1.89-6.77$ & $<0.001$ \\
\hline \multicolumn{7}{|c|}{ Distant Metastasis-Free Survival } \\
\hline & \multicolumn{3}{|c|}{ Univariate } & \multicolumn{3}{|c|}{ Multivariate * } \\
\hline Age & & & 0.513 & & & \\
\hline Sex & & & 0.314 & & & \\
\hline \multicolumn{7}{|l|}{ T stage } \\
\hline T2 vs. T1 & 2.01 & $0.75-5.38$ & 0.166 & & & \\
\hline T3 vs. T1 & 2.44 & $0.83-7.14$ & 0.104 & & & \\
\hline T4 vs. T1 & 3.84 & $1.38-10.7$ & 0.010 & & & \\
\hline \multicolumn{7}{|l|}{ N stage } \\
\hline N1 vs. N0 & & & 0.582 & & & \\
\hline N2a vs. N0 & & & 0.792 & & & \\
\hline N2b vs. N0 & 2.82 & $0.67-11.88$ & 0.157 & & & \\
\hline N2c vs. N0 & 3.76 & $0.85-11.67$ & 0.081 & & & \\
\hline N3 vs. N0 & 4.13 & $0.58-2.32$ & 0.156 & & & \\
\hline RPLN status (+ve vs. -ve) & 2.48 & $1.20-5.13$ & 0.014 & 2.68 & $1.29-5.57$ & 0.008 \\
\hline $\begin{array}{l}\text { Concurrent chemotherapy } \\
\text { (no vs. yes) } \\
\text { Smoking }\end{array}$ & 1.94 & $1.04-3.62$ & 0.037 & 1.94 & $1.03-3.65$ & 0.039 \\
\hline Former vs. never & 2.66 & $0.79-5.37$ & 0.138 & & & \\
\hline Current vs. never & 4.36 & $1.79-10.55$ & 0.001 & 4.17 & $1.71-10.16$ & 0.002 \\
\hline
\end{tabular}

${ }^{*}$ Factors with $p<0.2$ in univariate analysis included in multivariate model; $p$-values for these are shown in bold. Hazard ratio and confidence interval shown for factors $p<0.2$ carried forward into multivariate model. If factors were dropped as nonsignificant from multivariable analysis using backwards likelihood ratios, there were no $p$-values or HR to report. $\mathrm{HR}=$ hazard ratio; $\mathrm{CI}=$ confidence interval; $\mathrm{RPLN}=$ retropharyngeal lymph node.

\subsection{Cohort with $p 16$ Status}

Routine p16 testing was only introduced into clinical practice partway through this patient cohort and 226/402 (56.2\%) patients had p16 status available. Among patients, 192/226 (85.0\%) with p16 status available were p16 positive, and 21/192 (10.9\%) of patients with p16-positive tumours had abnormal RPLN. Outcomes for the 192 patients with proven p16-positive disease according to RPLN status are shown in Figure 2, with a nonsignificant trend for inferior outcomes for p16-positive patients with involved RPLN compared to those without. Three-year outcomes for patients with abnormal RPLN versus those without abnormal RPLN were OS $(77.4 \%$ versus $86.5 \%, p=0.059)$, DMFS $(83.2 \%$ versus $92.3 \%, p=0.214)$, local control $(85.0 \%$ versus $93.3 \%, p=0.194)$ and regional control $(85.0 \%$ versus $89.8 \%$, $p=0.343)$. Only 34 patients had proven p16-negative disease, of which $6 / 34$ (17.6\%) had abnormal 
RPLN. Three-year outcomes for patients with known p16-negative disease with RPLN were OS (66.7\% versus $64.7 \%, p=0.579)$, DMFS $(62.5 \%$ versus $81.3 \%, p=0.292)$, local control $(83.3 \%$ versus $69.8 \%, p=$ $0.858)$ or regional control $(60.0 \%$ versus $89.8 \%, p=0.390)$. Univariable analysis is shown in Table 3 . For the subgroup of p16-positive patients, the N stage was also converted to AJCC TNM8 [25]; there was no significant association between $\mathrm{N}$ stage and OS or DMFS (for OS, N1 vs. N0, $p=0.905 ; \mathrm{N} 2$ vs. N0, $p$ $=0.900 ; \mathrm{N} 3$ vs. N0, $p=0.891$; and for DMFS OS, N1 vs. N0, $p=0.940 ; \mathrm{N} 2$ vs. N0, $p=0.938$; N3 vs. N0, $p=0.931$ ). On multivariate analysis of the 226 patients with known p16 status (Table 3), ongoing smoking, p16 negative and more advanced T stage were associated with inferior OS. T stage and p16 status were independently associated with inferior DMFS.
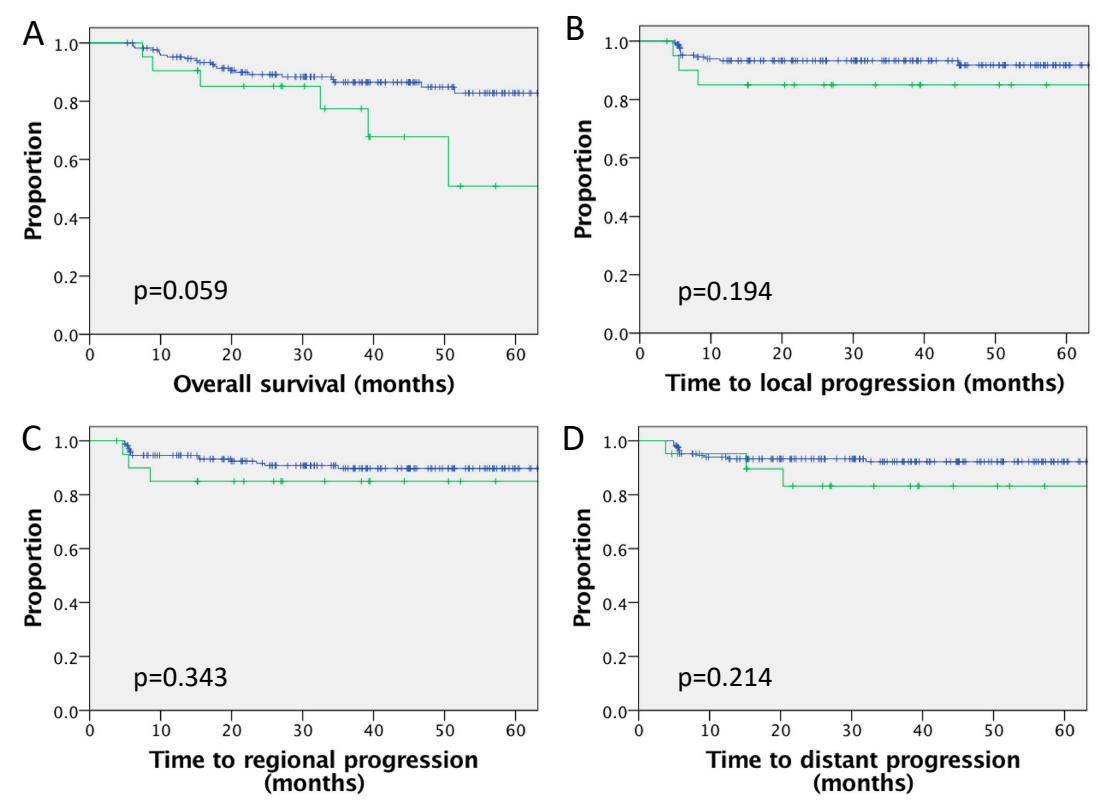

Figure 2. Survival outcomes for cohort of p16-positive $(n=192)$ disease comparing patients with or without RPLN involvement. Kaplan-Meier curves for (A) overall survival, (B) local (primary tumour) progression, $(\mathbf{C})$ regional (lymph node) progression and (D) distant metastatic progression. RPLN negative $(n=171)$ in blue and RPLN positive $(n=21)$ in green.

Table 3. Predictors of DMFS and OS in cohort with known p16 status ( $\mathrm{n}=226$, including 27 patients with RPLN involvement): Cox proportional hazards regression analysis with stepwise selection of established prognostic factors. Factors included in analysis: age, sex, T and N stage, use of concurrent chemotherapy, smoking status and presence of RPLN and HPV status.

\begin{tabular}{|c|c|c|c|c|c|c|}
\hline \multicolumn{7}{|c|}{ Overall Survival } \\
\hline & \multicolumn{3}{|c|}{ Univariate } & \multicolumn{3}{|c|}{ Multivariate * } \\
\hline & HR & $95 \%$ CI & $p$-Value & HR & $95 \%$ CI & $p$-Value \\
\hline Age & 1.03 & $0.99-1.06$ & 0.111 & & & \\
\hline Sex & 0.51 & $0.20-1.30$ & 0.158 & & & \\
\hline \multicolumn{7}{|l|}{ T stage } \\
\hline T2 vs. T1 & & & 0.324 & & & \\
\hline T3 vs. T1 & & & 0.379 & & & \\
\hline T4 vs. T1 & 4.59 & $1.51-13.97$ & 0.007 & 3.67 & $1.19-11.44$ & 0.024 \\
\hline \multicolumn{7}{|l|}{ N stage } \\
\hline N1 vs. N0 & & & 0.942 & & & \\
\hline N2a vs. N0 & & & 0.843 & & & \\
\hline N2b vs. N0 & & & 0.660 & & & \\
\hline N2c vs. N0 & & & 0.427 & & & \\
\hline N3 vs. N0 & & & 0.244 & & & \\
\hline
\end{tabular}


Table 3. Cont.

\begin{tabular}{|c|c|c|c|c|c|c|}
\hline \multicolumn{7}{|c|}{ Overall Survival } \\
\hline & \multicolumn{3}{|c|}{ Univariate } & \multicolumn{3}{|c|}{ Multivariate * } \\
\hline & HR & $95 \%$ CI & $p$-Value & HR & $95 \%$ CI & $p$-Value \\
\hline p16 status (-ve vs. +ve) & 2.48 & $1.19-5.14$ & 0.014 & 2.46 & $1.11-5.45$ & 0.026 \\
\hline RPLN status (+ve vs. -ve) & 2.11 & $0.97-4.59$ & 0.060 & & & \\
\hline $\begin{array}{l}\text { Concurrent chemotherapy } \\
\text { (no vs. yes) }\end{array}$ & 2.01 & $0.95-4.24$ & 0.066 & & & \\
\hline \multicolumn{7}{|l|}{ Smoking } \\
\hline Former vs. never & & & 0.553 & & & \\
\hline Current vs. never & 3.43 & $1.53-7.67$ & 0.003 & 2.41 & $1.03-5.65$ & 0.043 \\
\hline \multicolumn{7}{|c|}{ Distant Metastasis-Free Survival } \\
\hline & \multicolumn{3}{|c|}{ Univariate } & \multicolumn{3}{|c|}{ Multivariate * } \\
\hline Age & & & 0.37 & & & \\
\hline Sex & & & 0.64 & & & \\
\hline \multicolumn{7}{|l|}{ T stage } \\
\hline T2 vs. T1 & & & 0.242 & & & \\
\hline T3 vs. T1 & 6.24 & $0.75-51.80$ & 0.090 & & & \\
\hline $\mathrm{T} 4$ vs. T1 & 10.55 & $1.32-84.43$ & 0.026 & 11.36 & $1.42-91.04$ & 0.022 \\
\hline \multicolumn{7}{|l|}{ N stage } \\
\hline N1 vs. N0 & & & 0.934 & & & \\
\hline N2a vs. N0 & & & 0.95 & & & \\
\hline N2b vs. N0 & & & 0.935 & & & \\
\hline N2c vs. N0 & & & 0.934 & & & \\
\hline N3 vs. N0 & & & 0.93 & & & \\
\hline p16 status (-ve vs. +ve) & 2.84 & $1.16-6.98$ & 0.023 & 3.09 & $1.24-7.68$ & 0.015 \\
\hline RPLN status (+ve vs. -ve) & 2.41 & $0.86-6.53$ & 0.084 & & & \\
\hline $\begin{array}{l}\text { Concurrent chemotherapy } \\
\text { (no vs. yes) } \\
\text { Smoking }\end{array}$ & 2.07 & $0.76-5.61$ & 0.153 & & & \\
\hline Former vs. never & & & 0.833 & & & \\
\hline Current vs. never & 3.32 & $1.15-9.56$ & 0.026 & & & \\
\hline
\end{tabular}

${ }^{*}$ Factors with $p<0.2$ in univariate analysis included in multivariate model; $p$-values for these are shown in bold. Hazard ratio and confidence interval shown for factors $p<0.2$ carried forward into multivariate model. If factors were dropped as nonsignificant from multivariable analysis using backwards likelihood ratios, there were no $p$-values or HR to report. $\mathrm{HR}=$ hazard ratio; $\mathrm{CI}=$ confidence interval; $\mathrm{RPLN}=$ retropharyngeal lymph node.

\section{Discussion}

This study analysed the impact of RPLN involvement on outcomes in a large retrospective cohort of patients with oropharyngeal carcinoma treated with chemoradiotherapy. This is the largest reported series other than the two overlapping publications from the MD Anderson Cancer Centre [13,20]. The accurate identification of RPLN involvement is critical to this analysis. Determination of abnormal RPLN was based on established radiological criteria, including size, necrosis and FDG activity [20,23,26-28] by a dual-certified radiologist and nuclear medicine physician. Among patients, $84 \%$ in our series had a diagnostic MRI; MRI has been shown to be superior to contrast-enhanced CT for identification of RPLN metastases [11,29,30]. The most sensitive imaging modality for the identification of lymph node involvement in head and neck cancer is FDG PET-CT [31,32]. In one small series of patients who underwent retropharyngeal dissections, all patients who had evidence of FDG-avid RPLN on staging PET-CT had pathological RPLN involvement [19]. The imaging used in prior reported series to identify RPLN (Table 4) had varied widely and would be expected to impact upon the rates of RPLN identification. In several prior series examining the incidence of RPLN in oropharyngeal carcinoma, very limited numbers of patients had PET-CT staging [12,13,20,21]. In contrast, in our series, all patients had a staging PET-CT scan in addition to MRI and/or CT. Combining PET-CT with cross-sectional 
anatomical imaging with MRI or CT has been shown to increase the accuracy of RPLN detection [22,33]. Ours is the largest reported series in which all patients had a staging PET-CT; a considerably higher proportion of patients also had had a diagnostic MRI by comparison with other similar series (Table 4). In contrast, in the large series reported by Gunn et al. [13], only 29\% of patients had a PET and 9\% MRI with the majority of RPLN identified on the basis of CT alone; similarly, in the follow-up by Lin et al. [20], the majority of RPLN were identified only by CT.

A limited number of prior studies have reported RPLN involvement in oropharyngeal carcinoma, with a variable incidence (Table 4) [12-14,20-23,34]. In our series of 402 patients, the rate of radiological RPLN involvement was $10 \%$. This is very similar to the rate of RPLN involvement in the largest reported series from the MD Anderson Cancer Centre of 981 patients [13] of 10\% and their partially overlapping series of $781 \mathrm{HPV}$-positive patients with a rate of $9 \%$. Other reported series $[12,14,15,21,22]$ are considerably smaller than these of our series, which may at least partially explain the variability in the reported rates of RPLN involvement.

In the current analysis of the whole cohort, RPLN involvement was associated with significantly inferior OS in multivariate analysis. Although rates of local or regional disease control were numerically inferior in patients with RPLN involvement, differences were small and nonstatistically significant. Based upon the significant association of RPLN involvement with inferior DMFS in the absence of an association with local or regional control, it can be hypothesised that the impact upon OS of RPLN involvement is mediated via an increased risk of distant metastases (Figure 1), with which RPLN involvement was also independently associated in multivariate analysis.

HPV status is a key prognostic factor in oropharyngeal carcinoma [1]. Routine testing with p16 (as a surrogate for HPV status) was only introduced into routine practice partway through the period of this study and is only available for $56 \%$ of these patients. In patients tested, the rate of p16-positive disease is high at $85 \%$; therefore, it is likely that the prevalence of HPV-related disease in the overall cohort is high. Statistical analysis of the subgroup with proven p16-positive disease is limited by the size of the subgroup and the number of patients with abnormal RPLN ( $n=21 / 192)$. Within this p16-positive subgroup, a similar trend was observed to that in the overall cohort, with a trend toward inferior outcomes for patients with RPLN involvement (Figure 2), although differences were not statistically significant and RPLN involvement did not remain in the final model of multivariate analysis.

There are only a small number of series which have evaluated the prognostic impact of RPLN involvement; these are summarised in Table 4. The largest series of 981 patients from the MD Anderson Cancer Centre is based on patients treated between 2001 and 2007 and HPV data are not available [13]. This series reported that RPLN involvement was associated with inferior OS along with lower rates of local and distant disease control but not regional control in multivariate analysis. In this series, treatment approaches were heterogenous, including patients receiving short palliative radiotherapy schedules. In contrast, in our series, all patients received curative-intent treatment. The results from our analysis confirm the association of RPLN with DMFS and OS but, in contrast, did not demonstrate an association with local control. In a follow-up report focusing on 739 patients with HPV-positive and node-positive disease treated between 2004 and 2013 [20] (a partially overlapping series of patients with their original study), the presence of abnormal RPLN was associated with inferior OS and DMFS but not local or regional control in univariate analysis, although differences were not maintained in multivariate analysis. These data appear to support the finding in our series of the lack of association between RPLN and local control. The work of Lin et al. [20] and our data, therefore, suggest that although RPLN as a single variable was associated with inferior OS/DMFS in HPV-positive patients, the overall more favourable prognosis of HPV-positive disease made it difficult to detect statistically significant differences in relation to RPLN. In a series of 185 patients with HPV-positive disease from the University of Michigan [15], radiological RPLN involvement was associated with inferior OS and DMFS, with no difference in local or regional control. In contrast with the results of Lin et al. [20] and our subgroup of 192 patients with p16-positive disease, this association was maintained in multivariate analysis. The authors concluded that RPLN were an independent risk factor for the 
development of distant metastases and that this led to inferior failure-free and OS outcomes. A recent analysis of HPV-positive patients who were stage 1 according to the recent AJCC Cancer Staging, eighth edition [24] reported an association between RPLN involvement and distant metastases after adjusting for radiological extracapsular extension [35]. Other smaller studies [12,22] have shown trends toward inferior outcomes in patients with involved RPLN without significance in univariate [12] or multivariate analysis [22].

Overall, based upon our results and published data (Table 4), it appears that RPLN involvement is a risk factor particularly for the development of distant metastatic disease and, consequently, inferior overall outcomes whilst not being consistently predictive of locoregional control. In HPV-positive patients', similar trends were observed but differences in disease outcomes were smaller, likely relating to lower event rates, and statistical significance between RPLN involvement and outcomes was more difficult to demonstrate.

Table 4. Summary of literature reporting outcomes in relation to RPLN status.

\begin{tabular}{|c|c|c|c|c|c|}
\hline & & $\%$ RPLN+ & Imaging & Outcomes (RPLN+ versus RPLN-) & Summary \\
\hline Current study & $\begin{array}{l}\mathrm{n}=402(\mathrm{p} 16 \\
\text { available in } 226 \text {, of } \\
\text { which } 85 \% \text { p16+) }\end{array}$ & $10 \%$ & $\begin{array}{l}\text { PET-CT } 100 \% \\
\text { MRI } 84 \% \\
\text { CT } 21 \%\end{array}$ & $\begin{array}{c}\text { Five-year LC } 81.6 \% \text { vs. } 87.7 \%, p=0.154 \\
\text { Five-year RC } 80.7 \% \text { vs. } 85.4 \%, p=0.47 \\
\text { Five-year DMFS } 73.9 \% \text { vs. } 88.0 \%, p=0.011 \\
\text { Five-year PFS } 62.0 \% \text { vs. } 75.4 \%, p=0.002 \\
\text { Five-year OS } 67.1 \% \text { vs. } 79.1 \%, p=0.006 \\
\text { Significant on MVA for DMFS, OS } \\
\text { Nonsignificant trend for inferior DMFS, OS } \\
\text { in p16+ve subgroup }\end{array}$ & $\begin{array}{l}\text { RPLN associated with } \\
\text { increased risk DM and } \\
\text { inferior OS outcomes }\end{array}$ \\
\hline $\begin{array}{c}\text { Lin et al., } 2019 * \\
{[17]}\end{array}$ & $\begin{array}{c}\mathrm{n}=739 \mathrm{~N}+\text { and } \\
\mathrm{HPV}+\end{array}$ & $9 \%$ & $\begin{array}{l}\text { RPLN identified by } \\
\text { CT in } 66 \% \text {, PET-CT } \\
\text { in } 7 \% \text {, CT and } \\
\text { PET-CT in } 26 \% \text {, CT } \\
\text { and MRI in } 1 \%\end{array}$ & $\begin{array}{c}\text { Five-year LC } 96 \% \text { vs. } 94 \%, p=0.57 \\
\text { Five-year RC } 95 \% \text { vs. } 93 \%, p=0.47 \\
\text { Five-year DMFS } 84 \% \text { vs. } 93 \%, p=0.033 \\
\text { Five-year OS } 74 \% \text { vs. } 87 \%, p=0.008 \\
\text { Not significant for MVA } \\
\text { RP+ associated with inferior DMFS in } \\
\text { subgroup of smoking pack years }<10 \text { or } \\
\text { concurrent chemotherapy }\end{array}$ & $\begin{array}{l}\text { Difficult to } \\
\text { demonstrate } \\
\text { association with } \\
\text { outcome in HPV+ } \\
\text { group. RPLN+ may } \\
\text { not be suitable for } \\
\text { deintensification }\end{array}$ \\
\hline $\begin{array}{l}\text { Billfalk-Kelly et } \\
\text { al., } 2019 \text { [32] }\end{array}$ & $\begin{array}{c}\mathrm{n}=257, \mathrm{~T} 1-2, \mathrm{~N} 1 \\
\mathrm{HPV}+(\text { TNM8 stage } \\
1 \text { only) }\end{array}$ & $8 \%$ & CT 67\%MRI 33\% & $\begin{aligned} & \text { DFS: HR } 2.62, p= 0.021 . \text { Not significant for } \\
& \text { MVA } \\
& \text { Risk DM: bivariable analysis HR } 3.2, p=0.013\end{aligned}$ & $\begin{array}{l}\mathrm{RP}+\text { associated with } \\
\text { higher risk DM }\end{array}$ \\
\hline $\begin{array}{l}\text { Baxter et al., } \\
2015 \text { [19] }\end{array}$ & $\mathrm{n}=165 \mathrm{HPV}+$ & $10 \%$ & $100 \%$ PET-CT & $\begin{array}{l}\text { OR recurrence/death } 5.2 \\
\text { No significant association for MVA with } \\
\text { outcome }\end{array}$ & $\begin{array}{l}\mathrm{RP}+\text { not independently } \\
\text { associated with } \\
\text { outcome }\end{array}$ \\
\hline $\begin{array}{l}\text { Samuels et al., } \\
2015 \text { [12] }\end{array}$ & $\mathrm{n}=185 \mathrm{HPV}+$ & $16 \%$ & $67 \%$ PET-CT & $\begin{array}{l}\text { Five-year OS } 57 \% \text { vs. } 81 \%(p=0.02) \\
\text { Five-year FFS } 63 \% \text { vs. } 80 \%(p=0.015) \\
\text { Five-year DMFS } 70 \% \text { vs. } 91 \%(p=0.002) \\
\text { No difference local or regional failure } \\
\text { MVA: T4, N3 and RP+ independently } \\
\text { associated with OS and DMFS }\end{array}$ & $\begin{array}{l}\mathrm{RP}+\text { independent } \\
\text { prognostic factor for } \\
\mathrm{DM} \text {, translating into } \\
\text { inferior FFS/OS }\end{array}$ \\
\hline $\begin{array}{l}\text { Gunn et al., } \\
2013 *[10]\end{array}$ & $\begin{array}{c}\mathrm{n}=981(\mathrm{No} \mathrm{HPV} \\
\text { status) }\end{array}$ & $10 \%$ & $\begin{array}{l}\text { CT } 96 \% \\
\text { PET } 29 \% \\
\text { MRI } 9 \%\end{array}$ & $\begin{array}{c}\text { Five-year LC 79\% vs. } 92 \%, p<0.01 \\
\text { Five-year RC } 80 \% \text { vs. } 93 \%, p<0.01 \\
\text { Five-year DMFS } 66 \% \text { vs. } 89 \%, p<0.01 \\
\text { Five-year OS } 52 \% \text { vs. } 82 \%, p<0.01 \\
\text { Significant for MVA for LC }(p=0.023), \text { DMFS } \\
(p=0.003), \text { OS }(p=0.001)\end{array}$ & $\begin{array}{l}\text { RPLN associated with } \\
\text { inferior local } \\
\text { recurrence and OS, } \\
\text { increased risk of DM }\end{array}$ \\
\hline $\begin{array}{c}\text { Tang et al., } 2013 \\
\text { [9] }\end{array}$ & $\mathrm{n}=160$ (p16+ve: $\mathrm{n}=$ & $12 \%$ & $\begin{array}{l}\text { MRI } 46 \% \\
\text { PET-CT } 48 \% \\
\text { CT } 6 \%\end{array}$ & $\begin{array}{c}\text { Whole cohort: } \\
\text { Two-year OS 71\% vs. } 89 \% \text { (HR 2.4, } p=0.08 \text { ) } \\
\text { Two-year EFS 71\% vs. 81\% (HR 2.1, } p=0.08 \text { ) } \\
\text { p16+ve only: } \\
\text { Two-year OS HR 2.1, } p=0.23 \\
\text { Two-year EFS HR 2.0, } p=0.16\end{array}$ & $\begin{array}{c}\text { Nonsignificant trend to } \\
\text { worse OS, EFS for RP+ } \\
\text { in whole cohort and } \\
\text { p16+ subgroup }\end{array}$ \\
\hline
\end{tabular}

* Partially overlapping series; $\mathrm{RP}=$ retropharyngeal lymph nodes; $\mathrm{LC}=$ local control; $\mathrm{RC}=$ regional control; $\mathrm{DM}=$ distant metastases; DMFS = distant metastases-free survival; EFS = event-free survival; FFS = failure-free survival; OS = overall survival; PFS = progression-free survival; MVA = multivariate analysis; HPV = human papilloma virus; RPLN = retropharyngeal lymph node.

The limitations of this series include the retrospective nature of the analysis and the heterogeneity of treatment, including the use of induction and/or concurrent chemotherapy. Only $4 \%$ of patients were treated with induction chemotherapy, with no significant difference in the rate of RPLN involvement between those receiving/not receiving induction chemotherapy; therefore, it is not possible to draw any conclusions regarding the potential value of induction chemotherapy in the presence of RPLN disease. The absence of p16 status for $44 \%$ of patients limits the ability of analysis to detect significant associations of RPLN involvement with outcomes in both the p16-positive and -negative subgroups. However, in patients with known p16 status, the rate of p16 positivity was $85 \%$, with no statistical difference in the rate of RPLN involvement in patients without p16 status or p16+ve or p16-ve disease; 
this implies that analysis of the overall cohort remains informative. In addition, only a small number of patients had early stage disease (according to the TNM seventh edition classification in use at the time of treatment) and the applicability to this subgroup is limited. It was only possible to classify smoking history into non-, former and current smoking. There was insufficient detail in clinical notes to accurately assign the number of pack/years smoked which would be regarded as a gold standard for smoking history. We have previously reported on patterns of RPLN (ipsilateral, contralateral and bilateral) [16]; only a small number of patients have bilateral or contralateral-only lymph nodes precluding any analysis to determine whether these patterns have any prognostic implications beyond RPLN involvement per se.

Overall, based upon our results and published data (Table 4), it appears that RPLN involvement is a risk factor particularly for the development of distant metastatic disease and, consequently, inferior overall outcomes whilst not being consistently predictive of locoregional control. In HPV-positive patients, similar trends were observed but differences in disease outcomes were smaller, likely related to lower event rates, and statistical significance between RPLN involvement and outcomes is more difficult to demonstrate.

\section{Materials and Methods}

\subsection{Study Group}

This was a single-centre retrospective analysis at Leeds Cancer Centre. An electronic database was used to identify patients receiving chemoradiotherapy between January 2010 and June 2017 . Inclusion criteria for the analysis were oropharyngeal squamous cell carcinoma, curative treatment with radiotherapy \pm chemoradiotherapy, pretreatment staging FDG PET-CT and either contrast-enhanced MRI or CT of the neck or both. Exclusion criteria were prior radiotherapy or therapeutic surgery prior to baseline imaging. Electronic patient records were used to extract demographic and clinical data. Staging was documented according to the AJCC TNM staging, seventh edition in use during the study period [25]. Analysis of p16 immunohistochemistry was only implemented partway through this study period into routine clinical practice (due to the absence of data that p16 status should impact upon treatment). Scoring of p16 immunohistochemistry status was performed using a threshold of strong and diffuse nuclear and cytoplasmic staining in $\geq 70 \%$ of the tumour [36].

\subsection{Identification of Retropharyngeal Lymph Nodes}

Involvement of RPLN was determined by review of electronic records including imaging reports and also by review of LN gross tumour volumes (GTVs) in radiotherapy plans. Subsequently, all imaging for patients with suspected RPLN involvement was reviewed by a dual-certified radiologist and nuclear medicine physician with 15 years of experience of head and neck imaging. Normal lateral RPLNs are smaller than $4-4.5 \mathrm{~mm}$ in short axis [11]. Radiological criteria were used to identify involved RPLN and were defined for the study as short axis $\geq 5 \mathrm{~mm}$, necrosis $[20,26,27]$ and/or abnormal tracer uptake on PET-CT [23,28].

\subsection{Chemotherapy}

ICT was used for selected patients based upon clinician preference and patient and disease factors. The induction chemotherapy used was either TPF (docetaxel $75 \mathrm{mg} / \mathrm{m}^{2}$, cisplatin $75 \mathrm{mg} / \mathrm{m}^{2}$ and 5-flurouracil (5-FU) $750 \mathrm{mg} / \mathrm{m}^{2}$, days 2-5) [37] or PF (cisplatin $80 \mathrm{mg} / \mathrm{m}^{2}$ and 5-FU $800 \mathrm{mg} / \mathrm{m}^{2}$ ) [38]. Standard concurrent chemotherapy was cisplatin $100 \mathrm{mg} / \mathrm{m}^{2}$ (days 1 and 29). In the event of a contraindication to cisplatin, carboplatin area under the curve (AUC) 4 was substituted.

\subsection{Radiotherapy}

Radiotherapy techniques and the approach to target delineation changed several times during the study period of 2010-2017 with a conformal 3D-CT planned technique used in the early part of the 
time period, followed by 5-7 angle step-and-shoot intensity modulated radiotherapy (IMRT) and then replaced by volumetric modulated arc therapy (VMAT). The conformal 3D-CT planned technique has been previously described and used a compartmental approach to target volume delineation with the whole oropharynx and whole involved lymph node levels included within high dose volumes [39]. During the initial phase of IMRT implementation, a compartmental approach to target delineation was adopted based upon that used in the PARSPORT randomised trial [40,41]. This involved a primary tumour clinical target volume (CTV) including at least gross tumour volume (GTV) $+10 \mathrm{~mm}$, modified to anatomical boundaries and also encompassing the whole involved anatomical compartment (e.g., whole oropharynx, with the high dose nodal CTV including whole involved nodal levels). For some cases from 2014, at the discretion of the treating clinician and then routinely from 2016, a geometric (rather than routine inclusion of the whole oropharynx) approach to outlining was used with a high dose CTV based upon primary tumour and involved lymph nodes $+10 \mathrm{~mm}$ and lymph node levels treated within elective dose CTVs. The lymph node target routinely included levels $1 \mathrm{~b}-\mathrm{V}$ in the node-positive neck; nodal levels in a node-negative neck were selectively irradiated depending upon tumour site and disease extent according to published recommendations [42]. Our approach to elective irradiation of RPLN has changed over the time period of this study; in the initial part of the study, RPLNs were treated to the skull base in line with consensus guidelines [42], and the superior border was subsequently reduced to the top of hard palate/C1 in line with the consensus document [17]. Prior to 2014, bilateral RPLNs were routinely treated and, subsequently, contralateral RPLN in patients with no contralateral lymph node disease was spared at clinician discretion based upon emerging data [43]. Pharyngeal constrictor muscles were not outlined as an organ at risk and no deliberate attempt was made to minimise the dose to those regions.

The planning target volume (PTV) was created by autoexpansion of the CTV by $4 \mathrm{~mm}$ [16]. Standard dose fractionations were 70 Gy in 35 fractions over 7 weeks or an option of 65 Gy in 30 fractions over 6 weeks (for patients treated without concurrent chemotherapy, with lower doses to the prophylactic dose regions (54-63 Gy in 30-35 fractions over 6-7 weeks).

\subsection{Response Assessment and Follow-Up}

Response was routinely assessed 4 months after treatment by clinical examination, nasoendoscopy (if indicated) and FDG PET-CT; examination under anaesthetic and biopsies were performed on clinical discretion following response assessment. Patients were routinely followed up for at least 5 years prior to discharge.

\subsection{Statistical Analysis}

Analysis was performed using IBM SPSS Statistics, Version 24 (Armonk, NY, USA: IBM Corp.). Chi-squared and Mann-Whitney $U$ tests were used to investigate potential differences between clinical variables and the presence or absence of RPLN. Follow up and survival outcomes were calculated from the final day of radiotherapy. OS, progression-free survival (PFS), local control, regional control and DMFS were considered as endpoints and were calculated using the Kaplan-Meier method. Univariate and multivariate analyses were performed using Cox proportional hazards with backward likelihood ratios. Variables included age, sex, $\mathrm{T}$ and $\mathrm{N}$ stage, use of concurrent chemotherapy, smoking status, presence of RPLN and p16 status. Factors with $p<0.2$ in univariate analysis were included in the multivariate analysis. Multivariate analysis was performed separately with and without $\mathrm{p} 16$ as a factor given the smaller proportion of patients with p16 status available. A $p$-value of $<0.05$ was considered statistically significant.

\section{Conclusions}

In summary, radiological involvement of RPLN in patients with oropharyngeal carcinoma is an independent factor associated with a higher risk of development of distant metastases and inferior OS. This raises the possibility that patients with RPLN involvement may not be suitable candidates 
for deintensification of systemic therapy and may be considered as a prognostic marker to identify subgroups of patients at higher risk of development of distant disease. These findings require confirmation in prospective studies.

Author Contributions: Conceptualisation, A.F.S., S.V., M.A., K.E.D. and R.J.D.P.; methodology, Z.I.-E., L.J.M., M.A. and R.J.D.P.; formal analysis, L.J.M., Z.I.-E. and R.J.D.P.; investigation, Z.I.-E., L.J.M., M.A., K.E.D. and R.J.D.P.; writing — original draft preparation, R.J.D.P.; writing—review and editing, Z.I.-E., L.J.M., M.A., K.E.D., S.V. and A.F.S. All authors have read and agreed to the published version of the manuscript.

Funding: This research received no external funding.

Conflicts of Interest: The authors declare no conflict of interest.

\section{References}

1. Ang, K.K.; Harris, J.; Wheeler, R.; Weber, R.; Rosenthal, D.I.; Nguyen-Tan, P.F.; Westra, W.H.; Chung, C.H.; Jordan, R.C.; Lu, C.; et al. Human papillomavirus and survival of patients with oropharyngeal cancer. $N$. Engl. J. Med. 2010, 363, 24-35. [CrossRef] [PubMed]

2. Fakhry, C.; Westra, W.H.; Li, S.; Cmelak, A.; Ridge, J.A.; Pinto, H.; Forastiere, A.; Gillison, M.L. Improved survival of patients with human papillomavirus-positive head and neck squamous cell carcinoma in a prospective clinical trial. J. Natl. Cancer Inst. 2008, 100, 261-269. [CrossRef] [PubMed]

3. Mehanna, H.; Robinson, M.; Hartley, A.; Kong, A.; Foran, B.; Fulton-Lieuw, T.; Dalby, M.; Mistry, P.; Sen, M.; O'Toole, L.; et al. Radiotherapy plus cisplatin or cetuximab in low-risk human papillomavirus-positive oropharyngeal cancer (De-ESCALaTE HPV): An open-label randomised controlled phase 3 trial. Lancet 2019, 393, 51-60. [CrossRef]

4. Anderson, C.M.; Kimple, R.J.; Lin, A.; Karam, S.D.; Margalit, D.N.; Chua, M.L.K. De-Escalation Strategies in HPV-Associated Oropharynx Cancer-Are we Putting the Cart Before the Horse? Int. J. Radiat. Oncol. Biol. Phys. 2019, 104, 705-709. [CrossRef] [PubMed]

5. Mirghani, H.; Blanchard, P. Treatment de-escalation for HPV-driven oropharyngeal cancer: Where do we stand? Clin. Transl. Radiat. Oncol. 2018, 8, 4-11. [CrossRef]

6. Gillison, M.L.; Trotti, A.M.; Harris, J.; Eisbruch, A.; Harari, P.M.; Adelstein, D.J.; Sturgis, E.M.; Burtness, B.; Ridge, J.A.; Ringash, J.; et al. Radiotherapy plus cetuximab or cisplatin in human papillomavirus-positive oropharyngeal cancer (NRG Oncology RTOG 1016): A randomised, multicentre, non-inferiority trial. Lancet 2019, 393, 40-50. [CrossRef]

7. O'Sullivan, B.; Huang, S.H.; Siu, L.L.; Waldron, J.; Zhao, H.; Perez-Ordonez, B.; Weinreb, I.; Kim, J.; Ringash, J.; Bayley, A.; et al. Deintensification candidate subgroups in human papillomavirus-related oropharyngeal cancer according to minimal risk of distant metastasis. J. Clin. Oncol. 2013, 31, 543-550. [CrossRef]

8. Faraji, F.; Eisele, D.W.; Fakhry, C. Emerging insights into recurrent and metastatic human papillomavirus-related oropharyngeal squamous cell carcinoma. Laryngoscope Investig. Otolaryngol. 2017, 2, 10-18. [CrossRef]

9. O'Sullivan, B.; Adelstein, D.L.; Huang, S.H.; Koyfman, S.A.; Thorstad, W.; Hope, A.J.; Lewis, J.S., Jr.; Nussenbaum, B. First Site of Failure Analysis Incompletely Addresses Issues of Late and Unexpected Metastases in p16-Positive Oropharyngeal Cancer. J. Clin. Oncol. Off. J. Am. Soc. Clin. Oncol. 2015, 33, 1707-1708. [CrossRef]

10. Fakhry, C.; Zhang, Q.; Nguyen-Tan, P.F.; Rosenthal, D.; El-Naggar, A.K.; Garden, A.S.; Soulieres, D.; Trotti, A.; Avizonis, V.N.; Ridge, J.A.; et al. Reply to B. O'Sullivan et al. J. Clin. Oncol. 2015, 33, 1708-1709. [CrossRef]

11. Coskun, H.H.; Ferlito, A.; Medina, J.E.; Robbins, K.T.; Rodrigo, J.P.; Strojan, P.; Suarez, C.; Takes, R.P.; Woolgar, J.A.; Shaha, A.R.; et al. Retropharyngeal lymph node metastases in head and neck malignancies. Head Neck 2011, 33, 1520-1529. [CrossRef] [PubMed]

12. Tang, C.; Komakula, S.; Chan, C.; Murphy, J.D.; Jiang, W.; Kong, C.; Lee-Enriquez, N.; Jensen, K.C.; Fischbein, N.J.; Le, Q.T. Radiologic assessment of retropharyngeal node involvement in oropharyngeal carcinomas stratified by HPV status. Radiother. Oncol. 2013, 109, 293-296. [CrossRef] [PubMed]

13. Gunn, G.B.; Debnam, J.M.; Fuller, C.D.; Morrison, W.H.; Frank, S.J.; Beadle, B.M.; Sturgis, E.M.; Glisson, B.S.; Phan, J.; Rosenthal, D.I.; et al. The impact of radiographic retropharyngeal adenopathy in oropharyngeal cancer. Cancer 2013, 119, 3162-3169. [CrossRef] [PubMed] 
14. Bussels, B.; Hermans, R.; Reijnders, A.; Dirix, P.; Nuyts, S.; Van den Bogaert, W. Retropharyngeal nodes in squamous cell carcinoma of oropharynx: Incidence, localization, and implications for target volume. Int. J. Radiat. Oncol. Biol. Phys. 2006, 65, 733-738. [CrossRef]

15. Samuels, S.E.; Vainshtein, J.; Spector, M.E.; Ibrahim, M.; McHugh, J.B.; Tao, Y.; Schipper, M.; Worden, F.; Eisbruch, A. Impact of retropharyngeal adenopathy on distant control and survival in HPV-related oropharyngeal cancer treated with chemoradiotherapy. Radiother. Oncol. 2015, 116, 75-81. [CrossRef]

16. Iyizoba-Ebozue, Z.; Murray, L.J.; Arunsingh, M.; Vaidyanathan, S.; Scarsbrook, A.F.; Prestwich, R.J.D. Incidence and patterns of retropharyngeal lymph node involvement in oropharyngeal carcinoma. Radiother. Oncol. 2019. [CrossRef]

17. Gregoire, V.; Ang, K.; Budach, W.; Grau, C.; Hamoir, M.; Langendijk, J.A.; Lee, A.; Le, Q.T.; Maingon, P.; Nutting, C.; et al. Delineation of the neck node levels for head and neck tumors: A 2013 update. DAHANCA, EORTC, HKNPCSG, NCIC CTG, NCRI, RTOG, TROG consensus guidelines. Radiother. Oncol. 2014, 110, 172-181. [CrossRef]

18. Chung, E.J.; Kim, G.W.; Cho, B.K.; Cho, S.J.; Yoon, D.Y.; Rho, Y.S. Retropharyngeal lymph node metastasis in 54 patients with oropharyngeal squamous cell carcinoma who underwent surgery-based treatment. Ann. Surg. Oncol. 2015, 22, 3049-3054. [CrossRef]

19. Moore, E.J.; Ebrahimi, A.; Price, D.L.; Olsen, K.D. Retropharyngeal lymph node dissection in oropharyngeal cancer treated with transoral robotic surgery. Laryngoscope 2013, 123, 1676-1681. [CrossRef]

20. Lin, T.A.; Garden, A.S.; Elhalawani, H.; Elgohari, B.; Jethanandani, A.; Ng, S.P.; Mohamed, A.S.; Frank, S.J.; Glisson, B.S.; Debnam, J.M.; et al. Radiographic retropharyngeal lymph node involvement in human papillomavirus-associated oropharyngeal carcinoma: Patterns of involvement and impact on patient outcomes. Cancer 2019, 125, 1536-1546. [CrossRef]

21. Spector, M.E.; Chinn, S.B.; Bellile, E.; Gallagher, K.K.; Kang, S.Y.; Moyer, J.S.; Prince, M.E.; Wolf, G.T.; Bradford, C.R.; McHugh, J.B.; et al. Exploration for an Algorithm for Deintensification to Exclude the Retropharyngeal Site From Advanced Oropharyngeal Squamous Cell Carcinoma Treatment. JAMA Otolaryngol. Head Neck Surg. 2016, 142, 313-318. [CrossRef] [PubMed]

22. Baxter, M.; Chan, J.Y.; Mydlarz, W.K.; Labruzzo, S.V.; Kiess, A.; Ha, P.K.; Aygun, N.; Agrawal, N. Retropharyngeal lymph node involvement in human papillomavirus-associated oropharyngeal squamous cell carcinoma. Laryngoscope 2015, 125, 2503-2508. [CrossRef] [PubMed]

23. Tauzin, M.; Rabalais, A.; Hagan, J.L.; Wood, C.G.; Ferris, R.L.; Walvekar, R.R. PET-CT staging of the neck in cancers of the oropharynx: Patterns of regional and retropharyngeal nodal metastasis. World J. Surg. Oncol. 2010, 8, 70. [CrossRef] [PubMed]

24. AJCC Cancer Staging Manual, 8th ed.; Springer: New York, NY, USA, 2018.

25. AJCC Cancer Staging Manual, 7th ed.; Springer: New York, NY, USA, 2007.

26. Zhang, G.Y.; Liu, L.Z.; Wei, W.H.; Deng, Y.M.; Li, Y.Z.; Liu, X.W. Radiologic criteria of retropharyngeal lymph node metastasis in nasopharyngeal carcinoma treated with radiation therapy. Radiology 2010, 255, 605-612. [CrossRef] [PubMed]

27. Chua, D.T.; Sham, J.S.; Kwong, D.L.; Au, G.K.; Choy, D.T. Retropharyngeal lymphadenopathy in patients with nasopharyngeal carcinoma: A computed tomography-based study. Cancer 1997, 79, 869-877. [CrossRef]

28. Matsubara, R.; Kawano, S.; Chikui, T.; Kiyosue, T.; Goto, Y.; Hirano, M.; Jinno, T.; Nagata, T.; Oobu, K.; Abe, K.; et al. Clinical significance of combined assessment of the maximum standardized uptake value of F-18 FDG PET with nodal size in the diagnosis of cervical lymph node metastasis of oral squamous cell carcinoma. Acad. Radiol. 2012, 19, 708-717. [CrossRef] [PubMed]

29. Kato, H.; Kanematsu, M.; Watanabe, H.; Mizuta, K.; Aoki, M. Metastatic retropharyngeal lymph nodes: Comparison of CT and MR imaging for diagnostic accuracy. Eur. J. Radiol. 2014, 83, 1157-1162. [CrossRef]

30. Liao, X.B.; Mao, Y.P.; Liu, L.Z.; Tang, L.L.; Sun, Y.; Wang, Y.; Lin, A.H.; Cui, C.Y.; Li, L.; Ma, J. How does magnetic resonance imaging influence staging according to AJCC staging system for nasopharyngeal carcinoma compared with computed tomography? Int. J. Radiat. Oncol. Biol. Phys. 2008, 72, 1368-1377. [CrossRef]

31. Lonneux, M.; Hamoir, M.; Reychler, H.; Maingon, P.; Duvillard, C.; Calais, G.; Bridji, B.; Digue, L.; Toubeau, M.; Gregoire, V. Positron emission tomography with $\left[{ }^{18} \mathrm{~F}\right]$ fluorodeoxyglucose improves staging and patient management in patients with head and neck squamous cell carcinoma: A multicenter prospective study. J. Clin. Oncol. 2010, 28, 1190-1195. [CrossRef] 
32. Prestwich, R.J.; Sykes, J.; Carey, B.; Sen, M.; Dyker, K.E.; Scarsbrook, A.F. Improving target definition for head and neck radiotherapy: A place for magnetic resonance imaging and 18-fluoride fluorodeoxyglucose positron emission tomography? Clin. Oncol. 2012, 24, 577-589. [CrossRef]

33. Chu, H.R.; Kim, J.H.; Yoon, D.Y.; Hwang, H.S.; Rho, Y.S. Additional diagnostic value of (18)F-FDG PET-CT in detecting retropharyngeal nodal metastases. Otolaryngol. Head Neck Surg. 2009, 141, 633-638. [CrossRef] [PubMed]

34. Yoshimoto, S.; Kawabata, K.; Mitani, H.; Yonekawa, H.; Beppu, T.; Fukushima, H.; Sasaki, T. Treatment results for 84 patients with base of tongue cancer. Acta Otolaryngol. 2007, 127, 123-128. [CrossRef] [PubMed]

35. Billfalk-Kelly, A.; Yu, E.; Su, J.; O’Sullivan, B.; Waldron, J.; Ringash, J.; Bartlett, E.; Perez-Ordonez, B.; Weinreb, I.; Bayley, A.; et al. Radiologic Extranodal Extension Portends Worse Outcome in cN+ TNM-8 Stage I Human Papillomavirus-Mediated Oropharyngeal Cancer. Int. J. Radiat. Oncol. Biol. Phys. 2019, 104, 1017-1027. [CrossRef] [PubMed]

36. Singhi, A.D.; Westra, W.H. Comparison of human papillomavirus in situ hybridization and p16 immunohistochemistry in the detection of human papillomavirus-associated head and neck cancer based on a prospective clinical experience. Cancer 2010, 116, 2166-2173. [CrossRef]

37. Prestwich, R.J.; Oksuz, D.C.; Dyker, K.; Coyle, C.; Sen, M. Feasibility and Efficacy of Induction Docetaxel, Cisplatin, and 5-Fluorouracil Chemotherapy Combined With Cisplatin Concurrent Chemoradiotherapy for Nonmetastatic Stage IV Head-and-Neck Squamous Cell Carcinomas. Int. J. Radiat. Oncol. Biol. Phys. 2011, 81, e237-e243. [CrossRef]

38. Prestwich, R.J.; Kancherla, K.; Oksuz, D.C.; Williamson, D.; Dyker, K.E.; Coyle, C.; Sen, M. A single centre experience with sequential and concomitant chemoradiotherapy in locally advanced stage IV tonsillar cancer. Radiat. Oncol. 2010, 5, 121. [CrossRef]

39. Oksuz, D.C.; Prestwich, R.J.; Carey, B.; Wilson, S.; Senocak, M.S.; Choudhury, A.; Dyker, K.; Coyle, C.; Sen, M. Recurrence patterns of locally advanced head and neck squamous cell carcinoma after 3D conformal (chemo)-radiotherapy. Radiat. Oncol. 2011, 6, 54. [CrossRef]

40. Bayman, E.; Prestwich, R.J.; Speight, R.; Aspin, L.; Garratt, L.; Wilson, S.; Dyker, K.E.; Sen, M. Patterns of failure after intensity-modulated radiotherapy in head and neck squamous cell carcinoma using compartmental clinical target volume delineation. Clin. Oncol. 2014, 26, 636-642. [CrossRef]

41. Nutting, C.M.; Morden, J.P.; Harrington, K.J.; Urbano, T.G.; Bhide, S.A.; Clark, C.; Miles, E.A.; Miah, A.B.; Newbold, K.; Tanay, M.; et al. Parotid-sparing intensity modulated versus conventional radiotherapy in head and neck cancer (PARSPORT): A phase 3 multicentre randomised controlled trial. Lancet Oncol. 2011, 12, 127-136. [CrossRef]

42. Gregoire, V.; Levendag, P.; Ang, K.K.; Bernier, J.; Braaksma, M.; Budach, V.; Chao, C.; Coche, E.; Cooper, J.S.; Cosnard, G.; et al. CT-based delineation of lymph node levels and related CTVs in the node-negative neck: DAHANCA, EORTC, GORTEC, NCIC, RTOG consensus guidelines. Radiother. Oncol. 2003, 69, $227-236$. [CrossRef]

43. Spencer, C.R.; Gay, H.A.; Haughey, B.H.; Nussenbaum, B.; Adkins, D.R.; Wildes, T.M.; DeWees, T.A.; Lewis, J.S., Jr.; Thorstad, W.L. Eliminating radiotherapy to the contralateral retropharyngeal and high level II lymph nodes in head and neck squamous cell carcinoma is safe and improves quality of life. Cancer 2014, 120, 3994-4002. [CrossRef] [PubMed]

(C) 2019 by the authors. Licensee MDPI, Basel, Switzerland. This article is an open access article distributed under the terms and conditions of the Creative Commons Attribution (CC BY) license (http://creativecommons.org/licenses/by/4.0/). 